Short communication

\title{
Prevalence of malaria parasitemia and accuracy of microscopic diagnosis in Haiti, October 1995
}

\author{
S. Patrick Kachur, ${ }^{1}$ Elda Nicolas, ${ }^{2}$ Vély Jean-François, ${ }^{3}$ \\ Antonio Benitez, ${ }^{3}$ Peter B. Bloland, ${ }^{4}$ Yvan Saint Jean, ${ }^{2}$ \\ Dwight L. Mount, ${ }^{4}$ Trenton K. Ruebush II, ${ }^{4}$ and Phuc Nguyen-Dinh ${ }^{4}$
}

ABSTRACT In October 1995 the Ministry of Public Health and Population in Haiti surveyed 42 health facilities for the prevalence and distribution of malaria infection. They examined 1803 peripheral blood smears from patients with suspected malaria; the overall slide positivity rate was $4.0 \%$ (range, $0.0 \%$ to $14.3 \%$ ). The rate was lowest among 1 - to 4 -year-old children (1.6\%) and highest among persons aged 15 and older (5.5\%). Clinical and microscopic diagnoses of malaria were unreliable; the overall sensitivity of microscopic diagnosis was $83.6 \%$, specificity was $88.6 \%$, and the predictive value of a positive slide was $22.2 \%$. Microscopic diagnoses need to be improved, and adequate surveillance must be reestablished to identify areas where transmission is most intense. The generally low level of malaria is encouraging and suggests that intensified control efforts targeted to the areas of highest prevalence could further diminish the effect of malaria in Haiti.

Malaria has long been considered a major public health concern in Haiti (1), but reliable epidemiologic data about its current prevalence and distribution are limited $(2,3)$. Efforts to reduce malaria morbidity and mortality evolved from an eradication campaign (1961-1974), to a vertical control program (1974-1988), to an integrated primary health care approach (1988 to present). Annual rates of parasite inci-

\footnotetext{
Centers for Disease Control and Prevention, Division of Parasitic Diseases, Atlanta, Georgia, USA. Mailing address: Centers for Disease Control and Prevention, Mailstop F-22, 4770 Buford Highway, NE, Chamblee, Georgia 30341-3724, USA.

2 Ministry of Public Health and Population, Port-auPrince, Haiti.

3 Pan American Health Organization, Port-auPrince, Haiti.

4 Centers for Disease Control and Prevention, Division of Parasitic Diseases, Atlanta, Georgia, USA
}

dence declined during the eradication campaign but fluctuated at higher levels afterward (4). By the second half of the 1980s, the reported incidence of malaria in Haiti again declined $(5,6)$.

Recent political and social instability severely disrupted the nation's public health infrastructure and compromised disease reporting and control capabilities. The number of malaria cases reported to the World Health Organization dropped precipitously from 12306 in 1988 (7) to 987 in 1993 (8). Much of this decline is thought to be due to underreporting; some accounts suggest that there was a resurgence of malaria transmission in the early 1990s (9).

Since 1994, Haiti's national health officials have been working with international collaborators to reestablish disease reporting and control programs. Assessing the prevalence of malaria is a priority. The Ministry of Public Health and Population (MSPP) conducted a nationwide survey to measure the prevalence of malaria parasitemia among health facility patients with symptoms of the disease and to ascertain the accuracy of microscopic diagnoses.

The island of Hispaniola is the only place in the Caribbean where indigenous malaria transmission persists. The climate is tropical, with rainy and dry seasons, but intense deforestation has made it increasingly difficult to predict rain. Haiti is the poorest country in the Western Hemisphere; in 1991 its gross national product per capita was US\$370 (10). Most of the estimated 7 million residents live in 
rural areas. Nearly all human malaria infections in Haiti are caused by Plasmodium falciparum; chloroquine resistance has not been documented.

\section{STUDY DESIGN AND RESULTS}

Health facilities representing all nine administrative departments of the country were selected to participate in the National Malaria Prevalence Survey. Microscopists from each participating facility first attended a week-long workshop in Port-auPrince, where they reviewed the survey protocol and were retrained in standard techniques for collecting, staining, and interpreting peripheral blood smears. Between 23 and 27 October 1995, they prepared two thick peripheral blood smears from every patient with clinical symptoms of malaria. One smear from each patient was stained and examined by a health facility microscopist. Name, age, gender, address, temperature, and initial blood smear results for each patient were recorded on a registration form.

Duplicate smears were reserved for confirmatory examination by expert microscopists from the U.S. Centers for Disease Control and Prevention (CDC), who used a standard 30-min procedure and staining with $2 \%$ Giemsa. Their results were compared with the findings reported by microscopists at the health facilities.

Data from the registration forms and confirmatory smear examinations were recorded on a computerized database with the Epi Info software package, version 6.02 (11). As a measure of malaria prevalence, slide positivity rates (SPRs) - the proportion of blood smears with confirmed malaria parasitemia-were calculated for each facility and for the country as a whole. The results of the CDC microscopists were used as a standard, and the accuracy of health facility diagnoses was assessed by computing the sensitivity, specificity, predictive value of a positive slide, and predictive value of a negative slide. Bivariate statistical comparisons were based on a $\chi^{2}$ test at a 0.05 level of significance.
Forty-two health facilities collected data from 1894 patients, and 1803 duplicate blood smears were reviewed. $P$. falciparum parasites were identified in 72 of 1803 specimens for an overall confirmed SPR of $4.0 \%$. No other Plasmodium species were identified. SPRs are presented in Table 1. Four participating facilities provided $<10$ smears for review. Of the remain-

TABLE 1. Confirmed SPR at participating health facilities by Department, National Malaria Prevalence Survey, Haiti, October 1995

\begin{tabular}{|c|c|c|}
\hline Department and health facility location & Smears examined & SPR $(\%)$ \\
\hline Artibonite & 437 & 4.8 \\
\hline Deschapelles-site 1 & 93 & 2.2 \\
\hline Deschapelles-site 2 & 74 & 1.3 \\
\hline Gros Morne & 112 & 12.5 \\
\hline Gonaïves-site 1 & 46 & 0.0 \\
\hline Gonaïves-site 2 & 24 & 4.2 \\
\hline Liancourt & 79 & 4.1 \\
\hline Centre & 103 & 4.9 \\
\hline Congé & 16 & 0.0 \\
\hline Hinche & 20 & 10.0 \\
\hline Maïssade & 7 & 14.3 \\
\hline Mirebalais & 60 & 3.3 \\
\hline Grand Anse & 220 & 6.8 \\
\hline Baradères & 138 & 8.0 \\
\hline Chambellan & 19 & 5.3 \\
\hline Gebeau & 1 & 100.0 \\
\hline Jérémie & 19 & 10.5 \\
\hline Miragoane & 45 & 0.0 \\
\hline Nord & 327 & 2.4 \\
\hline Cap Haïtien & 40 & 0.0 \\
\hline Limbé-site 1 & 144 & 3.3 \\
\hline Limbé-site 2 & 53 & 0.0 \\
\hline Pignon & 47 & 6.4 \\
\hline Pilate & 11 & 0.0 \\
\hline Plain du Nord & 24 & 0.0 \\
\hline Port Margot & 7 & 0.0 \\
\hline Nord-Est & 7 & 14.3 \\
\hline Ouanaminthe & 7 & 14.3 \\
\hline Nord-Ouest & 311 & 1.6 \\
\hline Bassin Bleu & 53 & 0.0 \\
\hline Bombardopolis & 54 & 0.0 \\
\hline Bonneau & 62 & 3.2 \\
\hline Jean Rabel & 14 & 0.0 \\
\hline La Pointe & 81 & 3.7 \\
\hline Port de Paix & 17 & 0.0 \\
\hline St. Louis du Nord & 30 & 0.0 \\
\hline Ouest & 167 & 0.0 \\
\hline Croix des Bouquets & 26 & 0.0 \\
\hline Fermanthe & 24 & 0.0 \\
\hline Léogane & 36 & 0.0 \\
\hline Petit Goave & 44 & 0.0 \\
\hline Port-au-Prince-site 1 & 14 & 0.0 \\
\hline Port-au-Prince-site 2 & 19 & 0.0 \\
\hline Sud & 223 & 6.3 \\
\hline Camp Perrin & 20 & 0.0 \\
\hline Cavaillon & 15 & 0.0 \\
\hline Chantal & 71 & 11.3 \\
\hline Les Cayes-site 1 & 92 & 5.4 \\
\hline Les Cayes-site 2 & 24 & 4.2 \\
\hline Sud-Est & 21 & 14.3 \\
\hline Jacmel & 21 & 14.3 \\
\hline
\end{tabular}

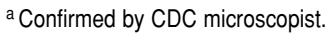


FIGURE 1. Location and confirmed SPR of participating health facilities, National Malaria Prevalence Survey, Haiti, October 1995; only 41 of the 42 participating facilities are illustrated (Gebeau is not included because only one smear was received from that location)

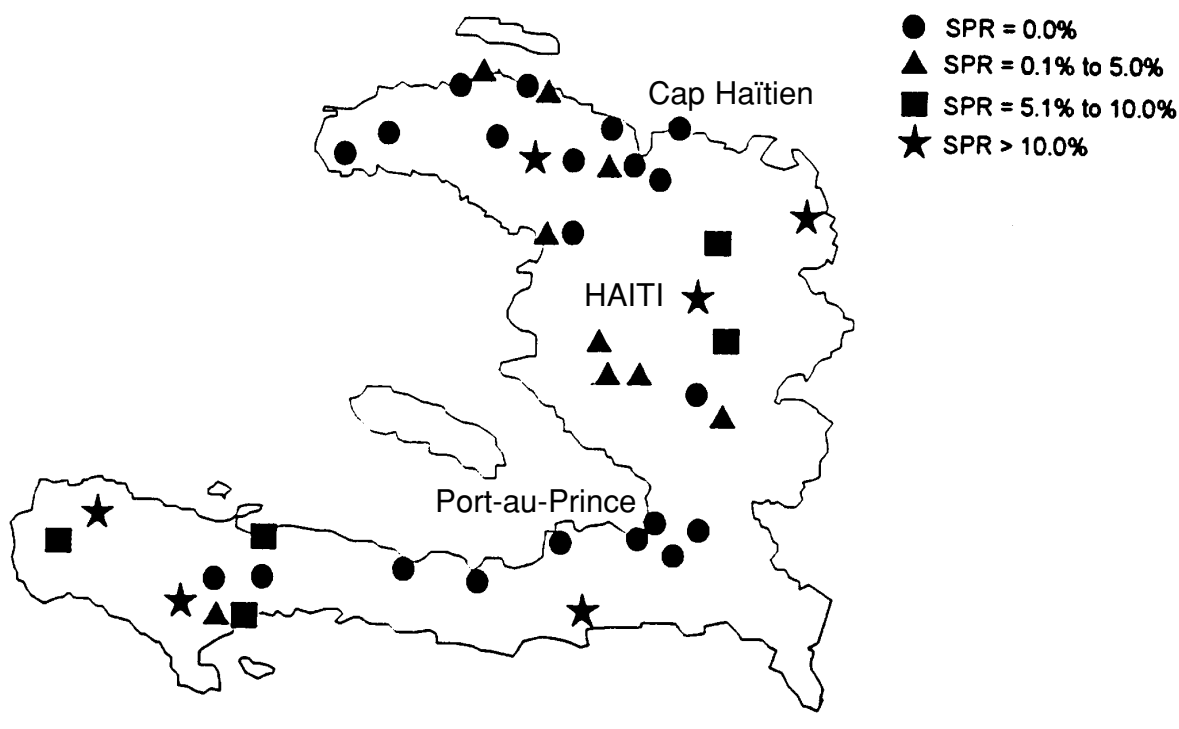

ing 38 facilities, 20 identified no positive smears, 9 documented SPRs of $0.1 \%$ to $5.0 \%, 5$ had SPRs of $5.1 \%$ to $10.0 \%$, and 4 facilities-Jérémie, Chantal, Gros Morne, and Jacmel-had SPRs $>10.0 \%$. The geographic distribution of the participating facilities is presented in Figure 1.

Table 2 indicates the number of study participants with confirmed positive blood smears according to age and gender. SPR was lower among

TABLE 2. Confirmed SPR by age and gender, National Malaria Prevalence Survey, Haiti, October $1995^{\mathrm{a}}$

\begin{tabular}{lccc}
\hline \multicolumn{1}{c}{ Variable } & $\begin{array}{c}\text { Participants with } \\
\text { positive smears }\end{array}$ & $\begin{array}{c}\text { Participants with } \\
\text { confirmatory smears }\end{array}$ & SPR (\%) \\
\hline $\begin{array}{l}\text { Gender } \\
\text { Female }\end{array}$ & $36(50.7 \%)$ & $930(54.8 \%)$ & 3.9 \\
$\quad$ Male & $35(49.3 \%)$ & $767(45.2 \%)$ & 4.6 \\
Median age & 19.5 years & 12.0 years & \\
Age distribution & & & \\
$\quad<1.00$ year & $6(8.3 \%)$ & $243(13.6 \%)$ & 2.5 \\
$1.00-4.99$ years & $6(8.3 \%)$ & $387(21.6 \%)$ & 1.6 \\
$5.00-14.99$ years & $17(23.6 \%)$ & $381(21.3 \%)$ & 4.5 \\
15.00 years or older & $43(59.7 \%)$ & $781(43.6 \%)$ & 5.5 \\
\hline
\end{tabular}

${ }^{a}$ Confirmed by CDC microscopist.

${ }^{b}$ Data on gender were missing for one participant with a positive smear and 106 with confirmatory smears.

${ }^{c}$ Age distribution of participants with confirmed positive smears differed significantly from age distribution of participants with negative smears: $\chi_{d f=3}^{2}=12.3 ; p=0.006$.

${ }^{d}$ Data on age were missing for 11 of the participants with confirmatory smears. health facility microscopists with those of the CDC microscopists who examined the duplicate confirmatory smears. No facility-based diagnosis was recorded for 292 of the 1803 smears collected, and 43 smears were unlabeled, leaving 1468 smears for comparison.

Of the 207 smears identified as positive by health facility microscopists, only 46 were confirmed; 161 were false-positives. Health facility microscopists identified negative smears more accurately; only 9 of 1261 were false-negatives. Nationwide the health facility microscopists detected malaria parasites with a sensitivity of $83.6 \%$ and a specificity of $88.6 \%$; predictive value positive was $22.2 \%$ and predictive value negative was $99.3 \%$. The sensitivities and predictive values positive for microscopic diagnosis at individual facilities ranged from $0.0 \%$ to $100 \%$. Individual health facility specificities from $36.7 \%$ to $100 \%$ were calculated and predictive values negative were consistently $>94 \%$.

\section{DISCUSSION}

This is the first step in an ongoing assessment of malaria in Haiti. Although practical factors limited the duration and geographic scope of the study, some preliminary conclusions can be drawn. First, clinical diagnosis appears to be an unreliable predictor of malaria parasitemia. All participants arrived at the facilities with symptoms of malaria and received a clinical diagnosis of malaria, but only $4.0 \%$ had detectable parasitemia. At most frontline health facilities (dispensaries and health centers) in Haiti, microscopic diagnosis is not available and all patients are treated for malaria if they have clinical symptoms of the disease. Thus, many patients who do not have malaria receive chloroquine; other conditions that could account for their symptoms may go undetected and untreated. A standard clinical definition of malarial illness would be helpful (12). Algorithms have been developed (13) for integrated management of malaria and other acute illnesses in 
childhood, but they need to be further evaluated and refined in settings of low malaria transmission. Similar algorithms for adults are needed.

Second, malaria was highly focal in the populations surveyed. Because few slides were received from some facilities, only limited conclusions can be drawn. Among the facilities that provided sufficient slides, some had SPRs of $>10.0 \%$, even though no malaria was detected at neighboring centers. The focal and seasonal distribution of malaria in Haiti is a known phenomenon (1), with important implications for its control. The nation has recently undergone striking environmental changes, which could affect the prevalence of infectious diseases, including malaria, as has occurred elsewhere $(14,15)$. Widespread deforestation and the changing land-use patterns that accompany large population shifts may influence the composition and behavior of vector populations and the usual patterns of seasonality. The season of high transmission may differ from year to year and in various parts of the country. Historically, malaria transmission peaks in November, December, or January in central Haiti (6); this survey was conducted for 5 days in October and should not be generalized to the entire year. Since this survey, the MSPP has worked to establish more permanent surveillance in selected health facilities where microscopic diagnosis is reliable.

Third, malaria transmission persists in Haiti but the prevalence may not be as high as in earlier periods $(5,7,8)$. Results fail to confirm speculation about a recent dramatic resurgence of malaria transmission (9). However, the findings should be interpreted with caution. Where transmission is low and highly focal, malaria prevalence can fluctuate widely. The study may have been conducted when all parts of the island were experiencing a period of low transmission, or an actual decrease in transmission caused by the environmental factors mentioned above could have occurred. Widespread use of antimalarial drugs also may have affected the results. Chloroquine and other pharmaceutical products are widely available, and many people treat themselves and their children. Frequent and early selftreatment may prevent some patients from becoming ill enough to seek medical attention and may shorten the duration of parasitemia. To assess the frequency of self-treatment with chloroquine among study participants, additional blood (100 $\mu \mathrm{l})$ was obtained from 79 consecutive patients at Liancourt; the samples were dried on filter paper and tested by high-performance liquid chromatography at the Division of Parasitic Diseases, CDC $(16,17)$. Thirty-one samples (39.2\%) contained chloroquine and desethylchloroquine-indicating that those patients recently took chloroquine.

Additional data suggest that malaria may be even less prevalent than the survey indicates. MSPP officials and collaborators conducted communitybased surveys in six communities between April and October 1995. On a single day in each community, they obtained blood smears from 50 to 120 residents; SPRs ranged from $0.0 \%$ to $1.4 \%$. Because patrons of health facilities are likely to include dispropor- tionate numbers of severely ill persons and patients who did not improve with self-treatment, a survey conducted in health facilities is not likely to represent the true level of malaria parasitemia in the general population.

Microscopic diagnosis in Haiti is clearly inadequate. Because of the low prevalence of malaria, control measures must be targeted to communities where it is most highly endemic, so it is important for diagnosis to be accurate. Additional training and supervision of health facility technicians should improve the accuracy of slidebased diagnoses. The results of this study can be used to identify facilities and microscopists most in need of additional training. Routine crosschecking of positive and negative blood smears is used in some control programs to monitor and improve the quality of microscopic diagnosis (18) and can form the basis for supervision and quality control. Such a system may be appropriate in Haiti but it requires timely review of blood smears by reliable microscopists.

MSPP officials are working to reestablish reliable, permanent surveillance which will better characterize geographic and seasonal distribution of malaria infection. Control activities could be stratified according to local prevalence rates (2). Malaria control activities in Haiti warrant serious and immediate consideration because it is the only nation in the region with high levels of $P$. falciparum and because of the potential for development of chloroquine resistance. Well-targeted, intensified malaria control activities might be effective in Haiti-possibly leading to elimination of the disease.

\section{REFERENCES}

1. Duverseau YT, Jean-François V, Benitez A. Formation pour la prevention de la malaria: diagnostic de la malaria. Port-au-Prince, Haiti: Pan American Health Organization; 1989. (PAHO/HAI/89/023).

2. Pan American Health Organization. Epidemiological stratification of malaria in the region of the Americas. Epidemiol Bull [PAHO] 1991;12:1-10.
3. Bawden MP, Slaten DD, Malone JD. Falciparum malaria in a displaced Haitian population. Trans R Soc Trop Med Hyg 1995;89: 600-603.

4. Pan American Health Organization. Status of malaria programs in the Americas, XLII report. Washington, DC: Pan American Health Organization; 1994. (Document CSP24/INF/2).
5. World Health Organization, Malaria Action Programme. World malaria situation, 1985. World Health Stat Q 1987;40:142-170.

6. Bonnlander H, Rossignol AM, Rossignol PA. Malaria in central Haiti: a hospital-based retrospective study 1982-1986 and 1988-1991. Bull Pan Am Health Organ 1994;28:9-16.

7. World Health Organization, Division of Control of Tropical Diseases. World malaria sit- 
uation, 1988. World Health Stat Q 1990;43: 68-78.

8. World Health Organization. World malaria situation in 1993, part II. Wkly Epidemiol Record 1996;71:25-29.

9. United States Agency for International Development, Haiti Mission. Pre-school children morbidity in selected health institutions. USAID Monit Rep 1995;4:5.

10. World Bank. World development report 1993: investing in health. New York: Oxford University Press; 1993.

11. Dean AG, Dean JA, Columbier D, Burton AH, Brend KA, Smith DC, Dicker RC, Sullivan KM, Fagan RF. Epi Info, version 6.02: a word processing, database and statistics program for epidemiology on microcomputers. Atlanta, GA: Centers for Disease Control and Prevention; 1994.
12. Gomes M, Espino FE, Abaquin J, Realon C, Salazar NP. Symptomatic identification of malaria in the home and in the primary health care clinic. Bull World Health Organ 1994; 72:383-390.

13. World Health Organization, Division of Diarrhoeal and Acute Respiratory Disease Control. Integrated management of the sick child. Bull World Health Organ 1995;73:735-740.

14. Marimbu J, Ndayiragije A, Le Bras M, Chaperon J. Environnement et paludisme au Burundi: à propos d'une épidémie de paludisme dans une région montagneuse non endemique. Bull Soc Pathol Exot 1993;86:399-401.

15. Jackson EK. Climate change and global infectious disease threats. Med J Aust 1995;163: 570-574.

16. Patchen LC, Mount DL, Schwartz IK, Churchill FC. Analysis of filter-paper-absorbed, finger- stick blood samples for chloroquine and its major metabolite using high-performance liquid chromatography with fluorescence detection. J Chromatogr 1983;278:81-89.

17. Lindstrom B, Ericsson O, Alvan G, Rombo L, Ekman L, Rais M, Sjoqvist F. Determination of chloroquine and its desethyl metabolite in blood: an application for samples collected in capillary tubes and dried on filter-paper. Therap Drug Monit 1985;7:207-210.

18. Gautam AS, Sharma RC, Bhatt RM, Gupta DK. Microscopic diagnosis of malaria in Kheda district of Gujarat. Indian I Malariol 1992;29:83-87.

Manuscript received on 24 September 1996. Revised version accepted for publication on 14 April 1997.

RESUMEN En octubre de 1995 el Ministerio de Salud Pública y Población de Haití inspeccionó 42 establecimientos de salud para determinar la prevalencia y distribución de la infección por malaria. Se examinaron 1803 frotis de sangre periférica obtenidos de pacientes con sospecha de tener esa enfermedad; la tasa general de positividad de los frotis fue de 4,0\% (con un recorrido de 0,0 a 14,3\%). La tasa más baja (1,6\%) se observó en el grupo de niños de 1 a 4 años y la más alta en personas de 15 años de edad o mayores (5,5\%). Los diagnósticos clínico y microscópico de la malaria fueron poco confiables; la sensibilidad general del diagnóstico microscópico fue de $83,6 \%$ y su especificidad de $88,6 \%$, y el valor predictivo de un frotis positivo fue de $22,2 \%$. Es preciso mejorar los diagnósticos microscópicos y reestablecer una vigilancia adecuada a fin de identificar las zonas donde la transmisión es más intensa. La frecuencia relativamente baja de la malaria es un dato alentador y sugiere que el refuerzo de las iniciativas de control dirigidas a las zonas de mayor prevalencia podría mitigar aun más el efecto de la malaria en Haití. 